\title{
Possible Correlations between the ULF Geomagnetic Signature and Mw6.4 Coastal Earthquake, Albania, on 26 November 2019
}

\author{
Dragoș Armand Stănică * and Dumitru Stănică *
}

check for

updates

Citation: Stănică, D.A.; Stănică, D. Possible Correlations between the ULF Geomagnetic Signature and Mw6.4 Coastal Earthquake, Albania, on 26 November 2019. Entropy 2021, 23, 233. https://doi.org/10.3390/ e23020233

Received: 14 January 2021

Accepted: 8 February 2021

Published: 17 February 2021

Publisher's Note: MDPI stays neutral with regard to jurisdictional claims in published maps and institutional affiliations.

Copyright: (c) 2021 by the authors. Licensee MDPI, Basel, Switzerland. This article is an open access article distributed under the terms and conditions of the Creative Commons Attribution (CC BY) license (https:// creativecommons.org/licenses/by/ $4.0 /)$.
Department of Electromagnetism and Lithosphere Dynamics, Institute of Geodynamics of the Romanian Academy, R-020032 Bucharest, Romania

* Correspondence: armand@geodin.ro (D.A.S.); dstanica@geodin.ro (D.S.); Tel.: +40-078-841-9041 (D.A.S.); $+40-078-825-5522$ (D.S.)

\begin{abstract}
An earthquake of Mw6.4 hit the coastal zone of Albania on 26 November 2019, at 02:54:11 UTC. It was intensively felt at about $34 \mathrm{~km}$ away, in Tirana City, where damages and lives lost occurred. To emphasize a pre-seismic geomagnetic signature before the onset of this earthquake, the data collected on the interval 15 October-30 November 2019, at the Panagjurishte (PAG)-Bulgaria and Surlari (SUA)-Romania observatories were analyzed. Further on, for geomagnetic signal identification we used the polarization parameter (BPOL) which is time invariant in non-seismic conditions and it becomes unstable due to the strain effect related to the Mw6.4earthquake. Consequently, BPOL time series and its standard deviations are performed for the both sites using ultra low frequency (ULF)fast Fourier transform (FFT) band-pass filtering. A statistical analysis, based on a standardized random variable equation, was applied to emphasize on the $\mathrm{BPOL}^{*}(\mathrm{PAG})$ and $\mathrm{ABS} \mathrm{BPOL}^{*}(\mathrm{PAG})$ time series the anomalous signal's singularity and, to differentiate the transient local anomalies due to the Mw6.4 earthquake, from the internal and external parts of the geomagnetic field, taken PAG observatory as reference. Finally, the ABS BPOL* (PAG-SUA) time series were obtained on the interval 1-30 November 2019, where a geomagnetic signature greater than 2.0, was detected on 23 November and the lead time was 3 days before the onset of the Mw6.4earthquake.
\end{abstract}

Keywords: ULF geomagnetic signature; Mw6.4earthquake; (PAG)-Bulgaria and Surlari (SUA)Romania geomagnetic data; $\mathrm{BPOL}$; $\mathrm{BPOL}^{*}$ and $\mathrm{BPOL}^{*}$ (PAG-SUA) time series

\section{Introduction}

The results carried out using ground-based geomagnetic data and ionospheric perturbations, associated with the catastrophic earthquakes Mw9.0 Tohoku, Japan on March 2011, Mw8.3 Coquimbo, Chile on September 2015 and Mw8.1Chiapas-Mexico, on September 2017 and the Vrancea seismicity, Romania, give useful information to elaborate a specific methodology able to emphasize possible inter-relations between the pre-seismic ultralow frequency (ULF) anomalous geomagnetic signature and the above-mentioned earthquakes [1-10], taking into account the following three possible earthquake generation mechanisms [11]: (a) piezomagnetic effect [12]; (b) magneto-hydrodynamic effect [13]; (c) Electrokinetic effect [14,15]. As regards the Mw 6.4 earthquake analysis, the following previously contributions at the EGU2020 "Sharing Geosphere Online" are briefly presented further on: a multi parameters analysis of satellite and ground based data (satellite thermal anomalies, atmospheric chemical potential, radon level variation, and very high frequency (VHF) propagation in lower atmosphere) which may supply significant information before an earthquake [16]; a statistical analysis applied to identify a precursory anomaly in the total electron content [17]; observations related to the lower ionospheric turbulence variations in the last half of 2019, in broader Balkan region [18]; INFREP Radio Network revealed variations in connection with six earthquakes ( $\mathrm{Mw}>5.0$ ) occurred in the Balkan Peninsula and Adriatic Sea on 26 and 27 November 2019 [19]; information regarding the pre-earthquake ionospheric anomalies by using the Romanian VLF/LF Infrep receivers 
and Gnss Global European Networks [20]; the results carried out by the satellite thermal monitoring of Balkan region by means of robust satellite technique-TIR anomalies in the framework of a multiparametric system are emphasized in [21]. All this information increases our knowledge about the origin of the different pre-seismic signals associated with the above-mentioned catastrophic earthquakes and, subsequently, in this study, the data collected from the two geomagnetic observatories Panagjurishte (PAG), Bulgaria and Surlari (SUA), Romania were analyzed in correlation with Mw6.4earthquake. Further on, to differentiate a pre-seismic anomalous signal associated with this earthquake, a statistical analysis based on the standardized random variable equation, taken observatory PAG as reference, was applied. Finally, it must be mentioned that an anomalous interval, having an apex on 23 November, 2019 on all the following time series of BPOL (PAG), BPOL* (PAG), ABS BPOL* (PAG), and ABS BPOL* (PAG-SUA) was identified, with 3 days before the earthquake occurrence on 26 November, 2019.

\section{Material and Methods}

A major earthquake of Mw6.4, which was generated at about $10 \mathrm{~km}$ depth, hit the coastal zone of Albania on 26 November, 2019 at 02:54:11 UTC, as it was determined by the Euro Mediterranean Seismic Centre (http:/ /www.emsc-csem.org). The main shock was felt in Montenegro, Italy, and Greece (Corfu Island), and it has been followed by more than 100 after-shocks, from which 22 had magnitudes larger than Mw4.0 and four with $\mathrm{Mw} \geq 5.0$. Both the earthquake epicenter and hypocenter were located near the coastal zone of Albania, at about $30 \mathrm{~km}$ distance from the capital city Tirana (Figure 1) and, respectively, on the Adriatic plate subduction zone [22] (Figure 2).

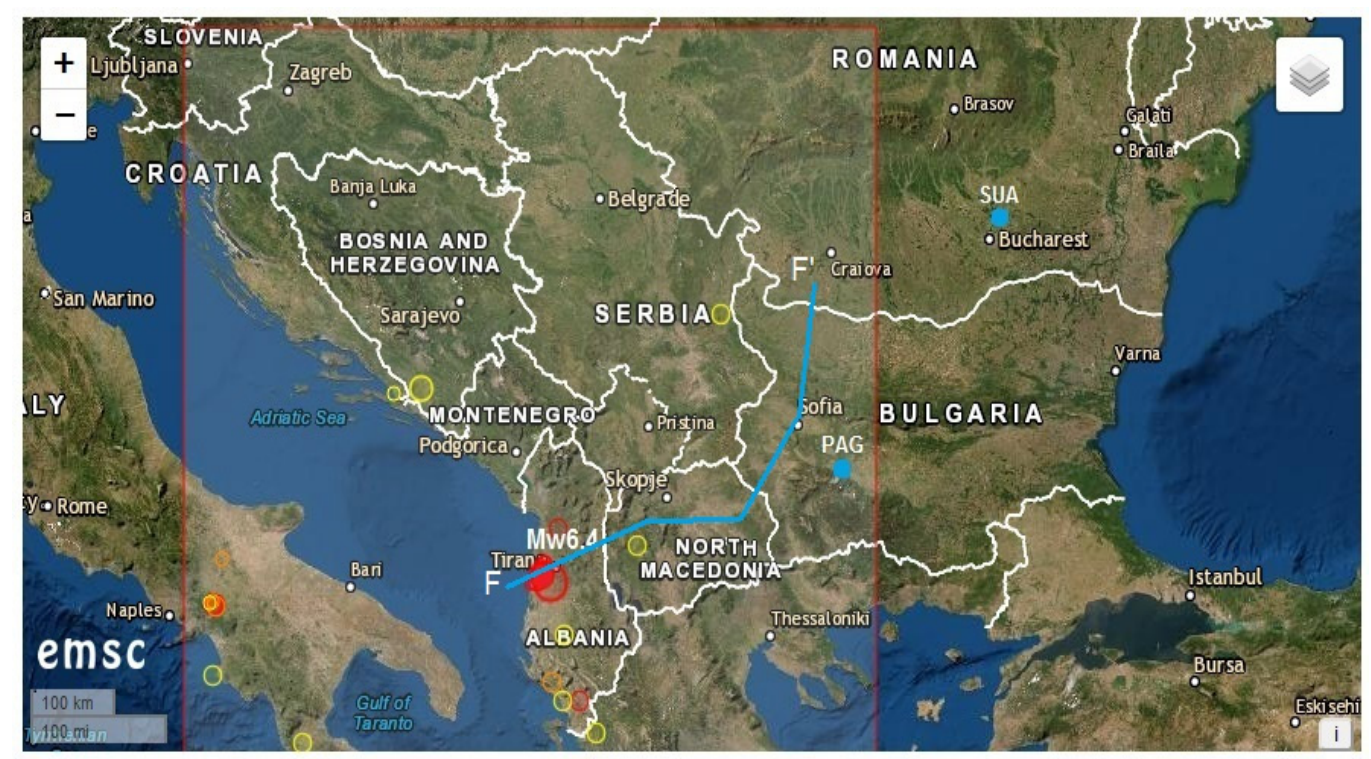

Figure 1. The placements of the Mw6.4 earthquake (red full circle), the geomagnetic observatories Panagjurishte (PAG), Bulgaria and Surlari (SUA), Romania (blue marks) and F-F' profile (blue line) on the Euro Mediterranean Seismic Centre (EMSC) map. 


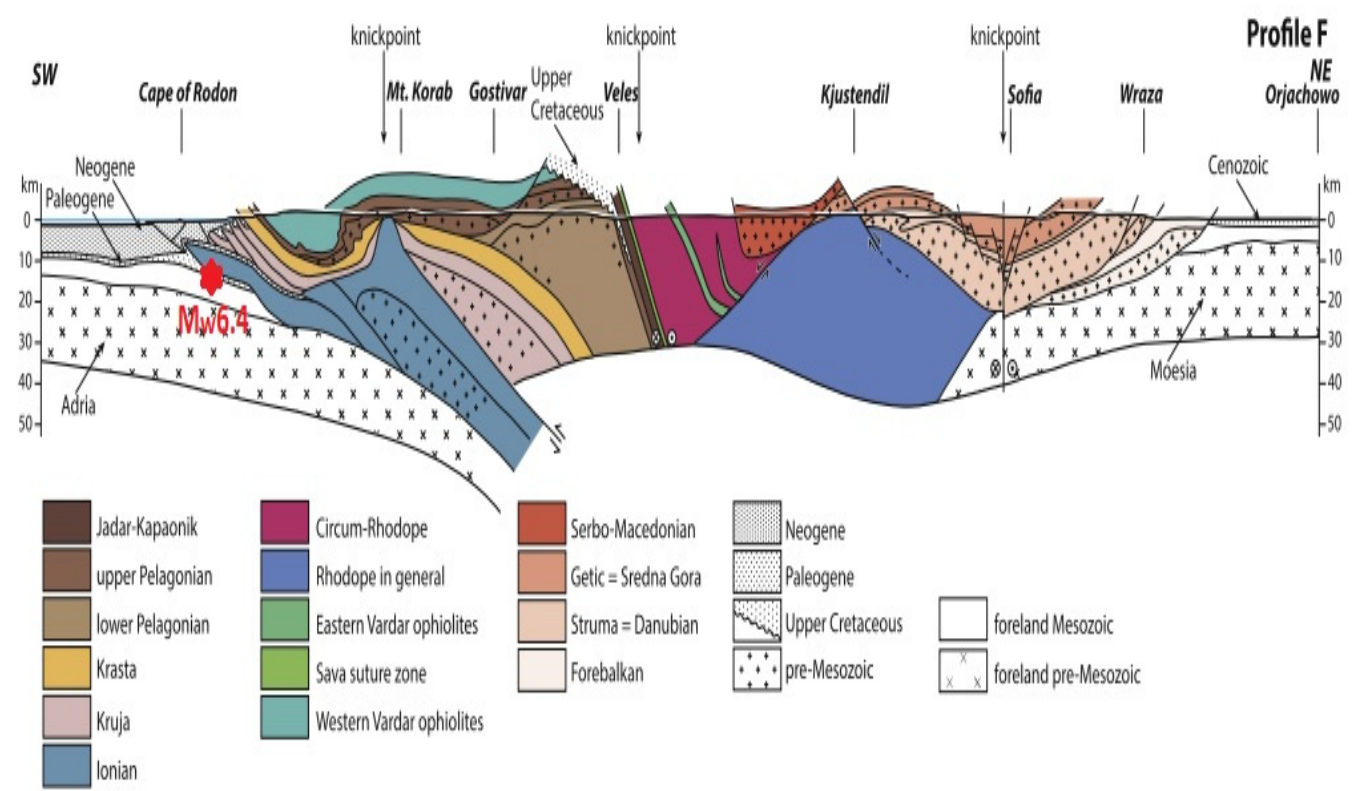

Figure 2. Geotectonic cross-section emphasizing the Mw6.4 earthquake location (red star) on the Adria plate subduction zone, along the profile F - F' in Figure 1, SW is South-West, NE is North-West, see [22].

\section{Basic Theoretical Concepts}

To identify pre-seismic geomagnetic signature associated with the Mw6.4earthquake, in this paper, the geomagnetic data were collected, on the interval 15 October-30 November, 2019, via the internet (http:/ / www.intermagnet.org), from the geomagnetic observatories Panagjurishte (PAG), Bulgaria and Surlari (SUA), Romania, and the following relations were used:

(a) Polarization parameter (BPOL) expressed as:

$$
\operatorname{BPOL}(\mathrm{f})=\mathrm{Bz}(\mathrm{f}) / \mathrm{SQRT}\left[\left(\mathrm{Bx}^{2}(\mathrm{f})+\mathrm{By}^{2}(\mathrm{f})\right]\right.
$$

where $\mathrm{Bx}, \mathrm{By}$, and $\mathrm{Bz}$ are horizontal and vertical components of the geomagnetic field in $\mu \mathrm{T}, \mathrm{f}$ is frequency in $\mathrm{Hz}$ [23]. For a given 2D geoelectric structure the vertical magnetic component $(\mathrm{Bz})$ is a totally secondary field being essentially produced by the horizontal magnetic components (Bx, By) and, consequently, BPOL is time invariant in non-seismic conditions that becomes unstable before the onset of the seismic event. In our case, the 2-D structure from the contact between the tectonic units of the Alpine collision zone and the Adria Plate subduction boundary, Figure 2, generates an increased anomalous distribution of BPOL. Its magnitude is proportional with the geoelectric current intensity, due to the tectonic stress generated by the Mw6.4 earthquake

(b) Distance ( $R$ ) between the observatories and earthquake epicenter is taken into consideration according to the Relation (2), given in [24]

$$
R(\mathrm{~km})=10^{0.5 \mathrm{M}-0.27}
$$

where $R$ is epicentral distance and $\mathrm{M}$ is earthquake magnitude.

In conformity with Relation (2), the strain effect associated with the Mw6.4 earthquake may be detected up to $800 \mathrm{~km}$. In this case, distances between epicenter and PAG observatory is $450 \mathrm{~km}$ and for SUA is about $750 \mathrm{~km}$, respectively, then there are conditions to identify a pre-seismic geomagnetic signature, taking PAG observatory as reference.

The parameters used in this paper in order to identify the precursory geomagnetic anomalies are presented as follows: BPOL (PAG), BPOL (SUA) with their standard devia- 
tions (SD), BPOL* $(\mathrm{PAG}), \mathrm{ABS} \mathrm{BPOL}^{*}(\mathrm{PAG})$, and BPOL* (PAG-SUA) are obtained by the next procedures:

FFT-BPF (fast Fourier transform-band pass-filtering) analysis in the ULF (ultra -low frequency) range $(0.001-0.0083 \mathrm{~Hz})$ was performed for the two observatories and an example is presented in Figure 3, for PAG observatory

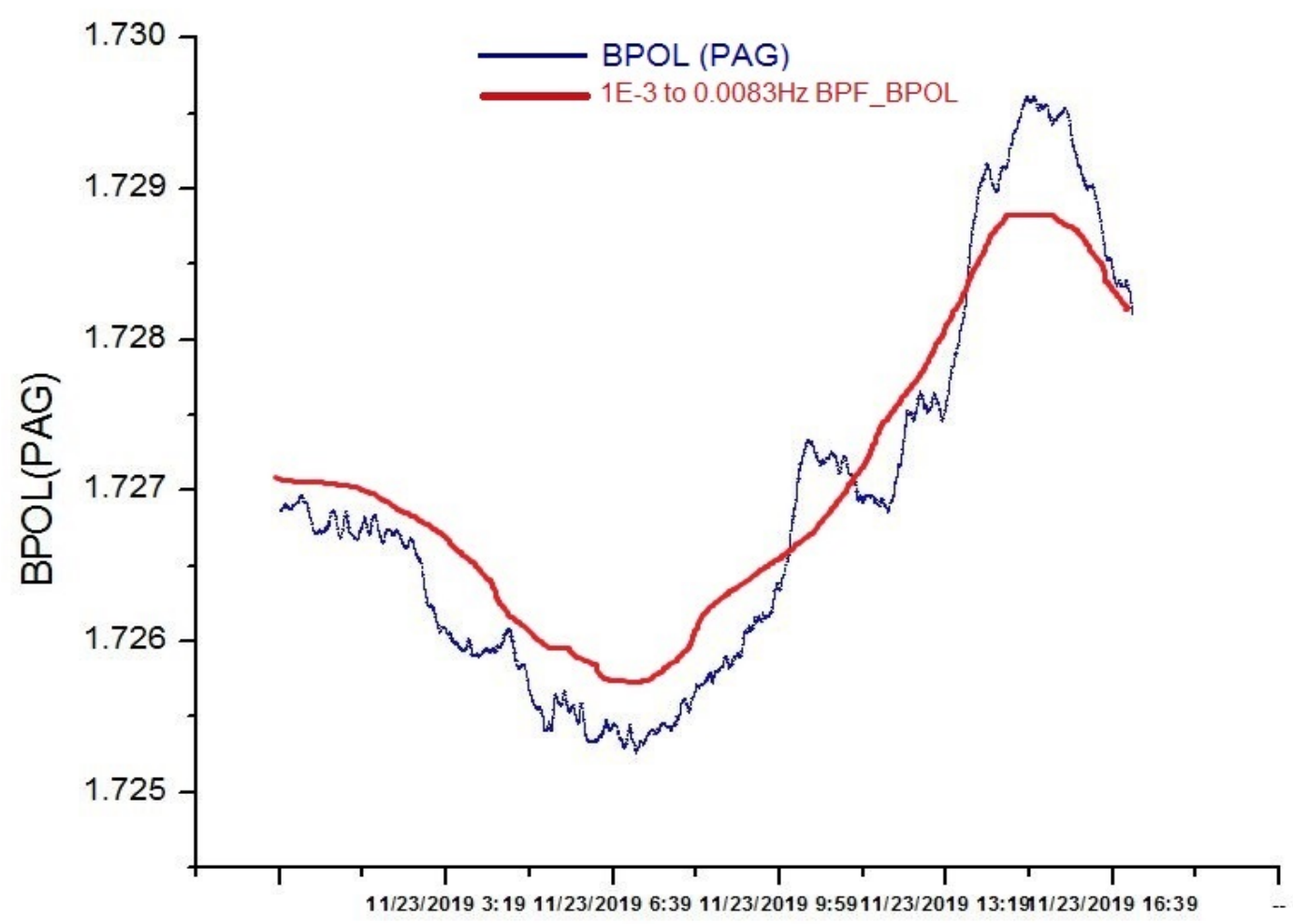

Day and Time

Figure 3. FFT (fast Fourier transform) band-pass filtering (red line) applied on BPOL (PAG) (geomagnetic polarization parameter) distribution for a time window of 1024 samples $(\Delta t=60 \mathrm{~s})$, recorded on 23 November 2019.

Statistical analysis based on the standardized random variable equation (Relation 3) to fulfil two objectives:

- $\quad$ to identify geomagnetic precursory signal triggered by Mw6.4 earthquake, that may be observed in the both mentioned observatories, by means of the following relation:

$$
\mathrm{BPOL}^{*}=(\mathrm{X}-\mathrm{Y}) / \mathrm{W}
$$

The explanation for $X, Y, W$ may be seen in [8]:

- to separate the precursory seismic signals from the ionospheric and terrestrial geomagnetic field variations, taking PAG observatory as reference, according to the Relation (4):

$$
\mathrm{BPOL}^{*}(\mathrm{PAG}-\mathrm{SUA})=(\mathrm{A}-\mathrm{B}) / \mathrm{C}
$$

The explanation for the A, B, C, may be also found in [8].

\section{Results}

In this paper, the geomagnetic precursor is considered be generated by the electrical conductivity changes, due to the earthquake generation mechanism that may induce a tectonic stress deployed along the Adria Plate subduction zone (Figure 2). Based on 
relations (1), (3), (4), in the next three sections (Section 3.1, Section 3.2, Section 3.3), the preseismic geomagnetic signatures related to Mw6.4 earthquake are presented.

\subsection{BPOL (PAG) and BPOL (SUA) Time Series Carried Out Using Relation (1)}

The graphic representations of the BPOL (PAG) and BPOL (SUA) time series led to a comprehensive image on the applied methodology, so as it may be seen in Figures 4 and 5 .

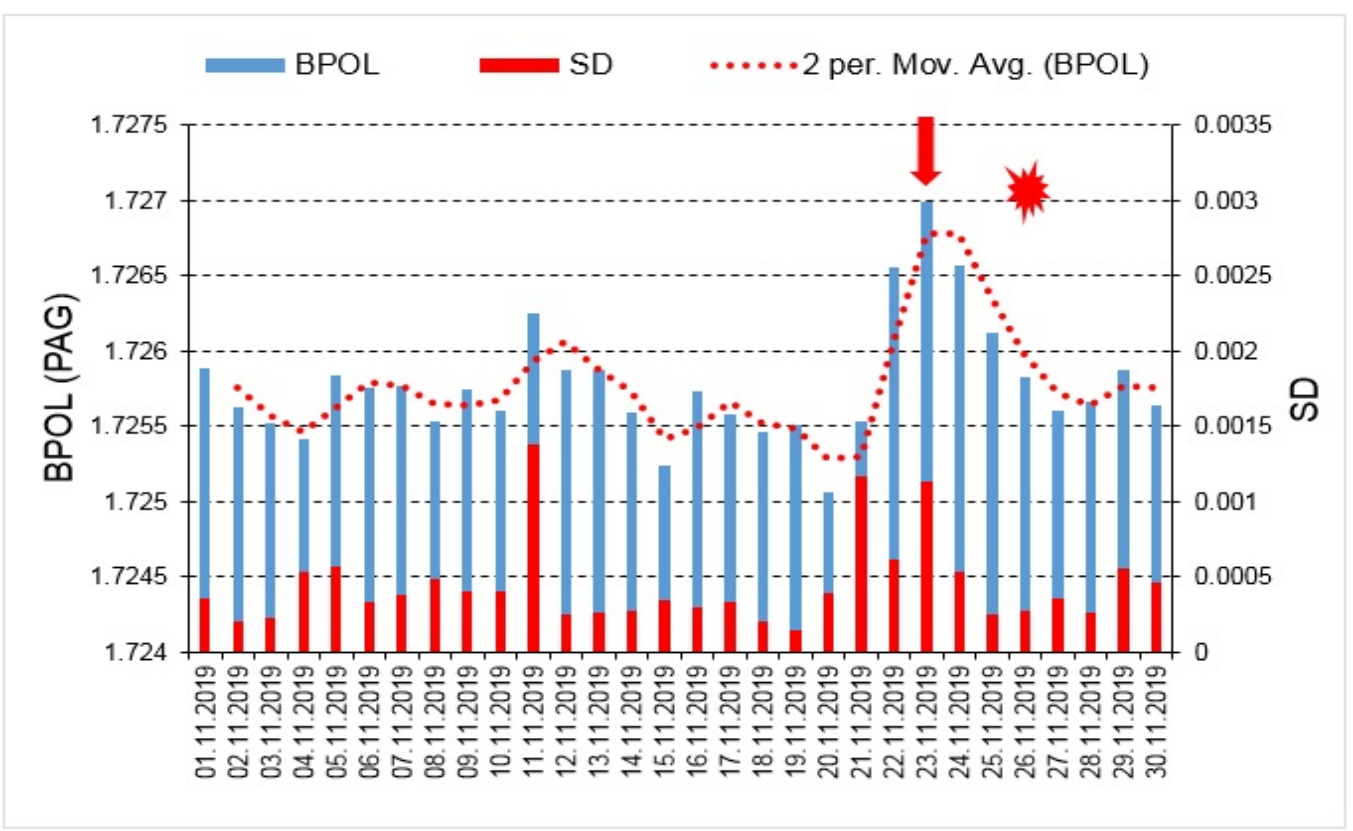

Figure 4. BPOL (PAG) and its standard deviation (SD) time series carried out on the interval 1-30 November 2019; vertical red arrow indicates a pre-seismic anomalous signature on 23 November, 2019; red star is Mw6.4 earthquake; red dotted line is 2 days averaged distribution of BPOL.

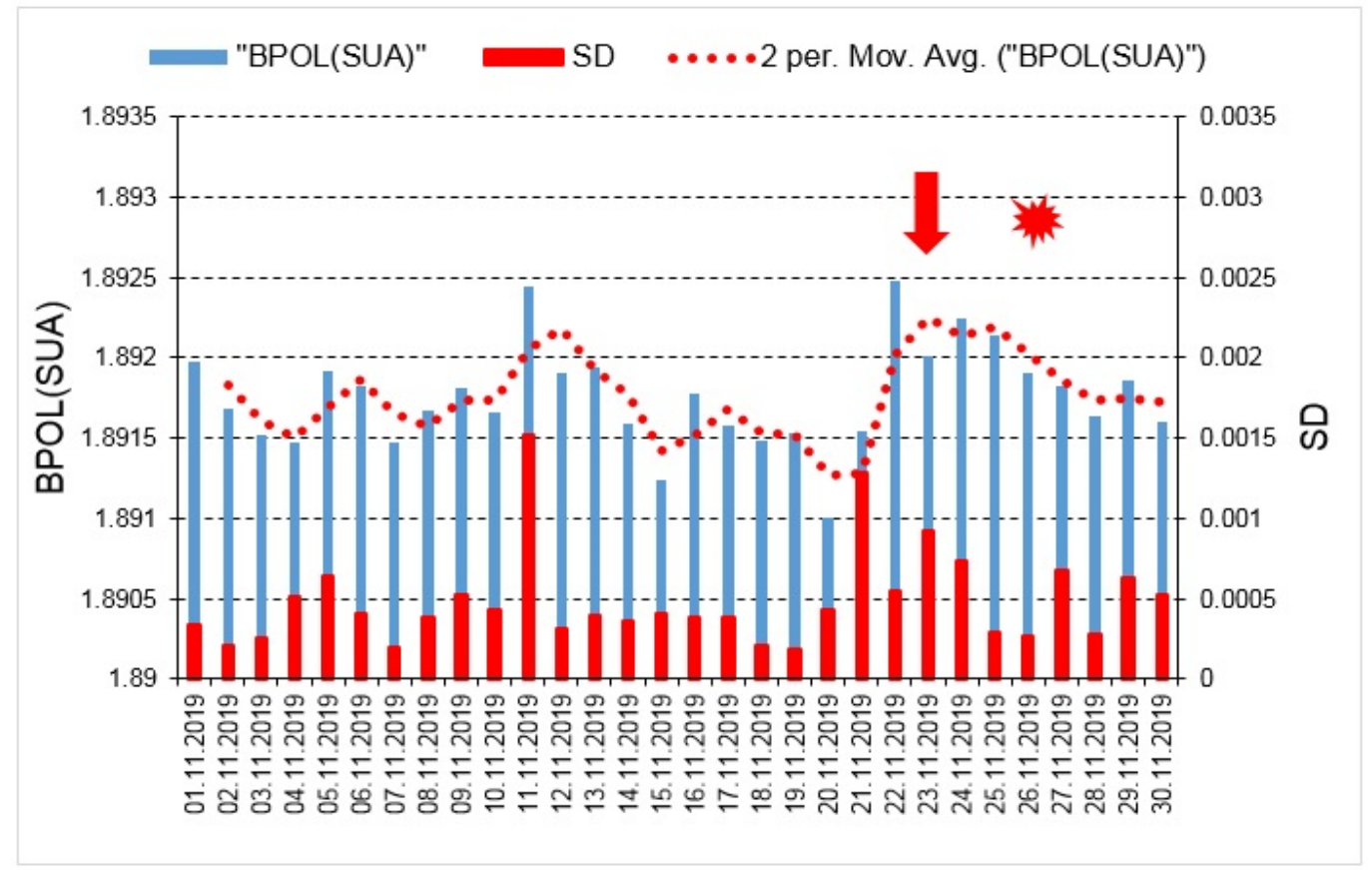

Figure 5. BPOL (SUA) and its standard deviation (SD) time series carried out on the interval 1-30 November 2019; for additional information see Figure 4 caption. 


\section{2. $\mathrm{BPOL}^{*}(P A G)$ and $A B S B P O L^{*}(P A G)$ Time Series Carried Out Using Relation (3)}

The graphic models for the BPOL* ${ }^{*}(\mathrm{PAG}), \mathrm{ABS}_{\mathrm{BOPL}}^{*}(\mathrm{PAG})$ presented in Figures 6 and 7 put into evidence the precursory geomagnetic anomalies.

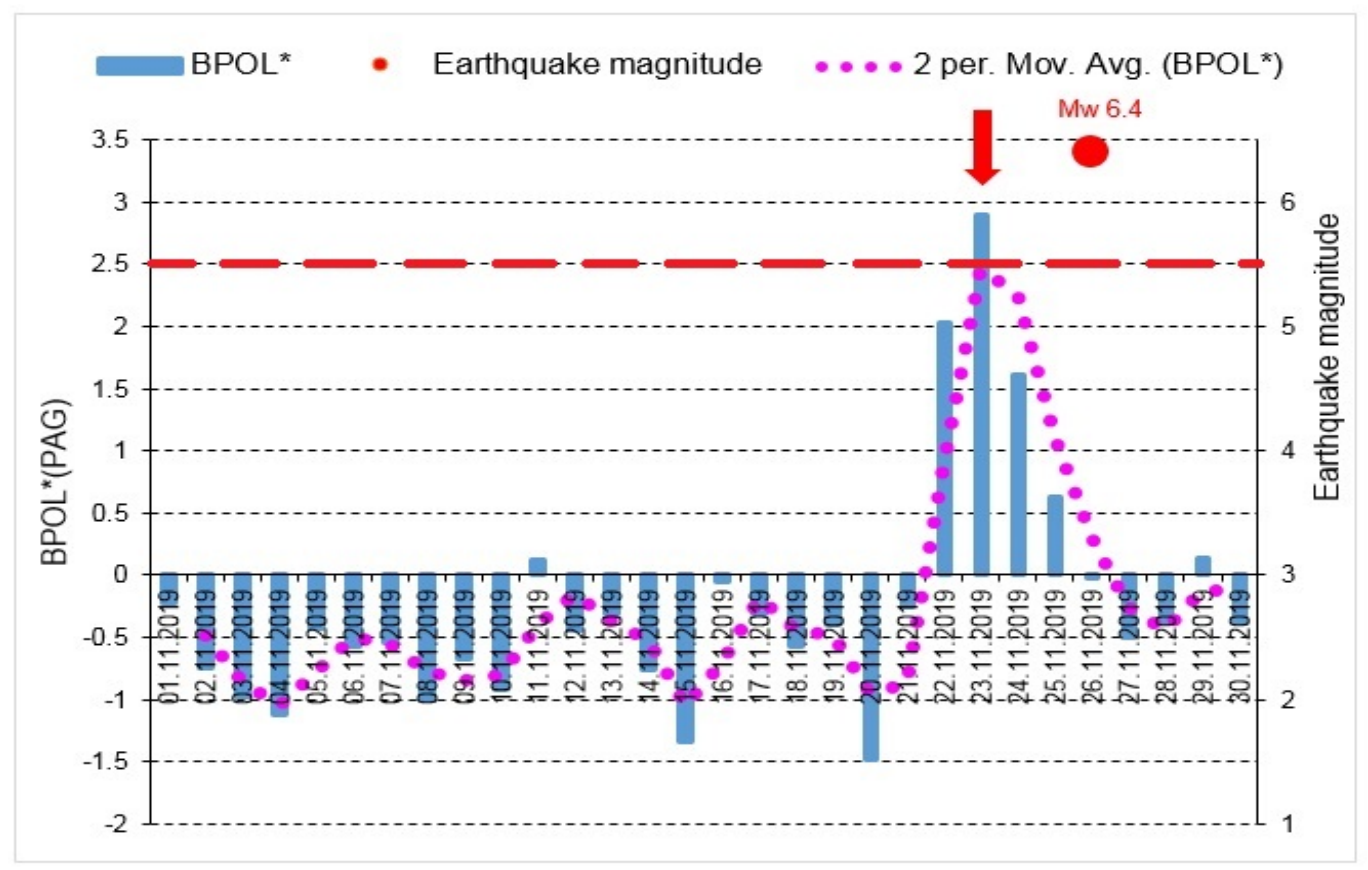

Figure 6. $\mathrm{BPOL}^{*}(\mathrm{PAG})$ time series carried out on the interval 1-30 November 2019; vertical red arrow indicates a preseismic anomalous signature on 23 November, 2019; red full circle is Mw6.4earthquake; dotted pink line is 2 days averaged distribution of $\mathrm{BPOL}^{*}$; red dashed line is threshold for anomaly using standard deviation (SD).

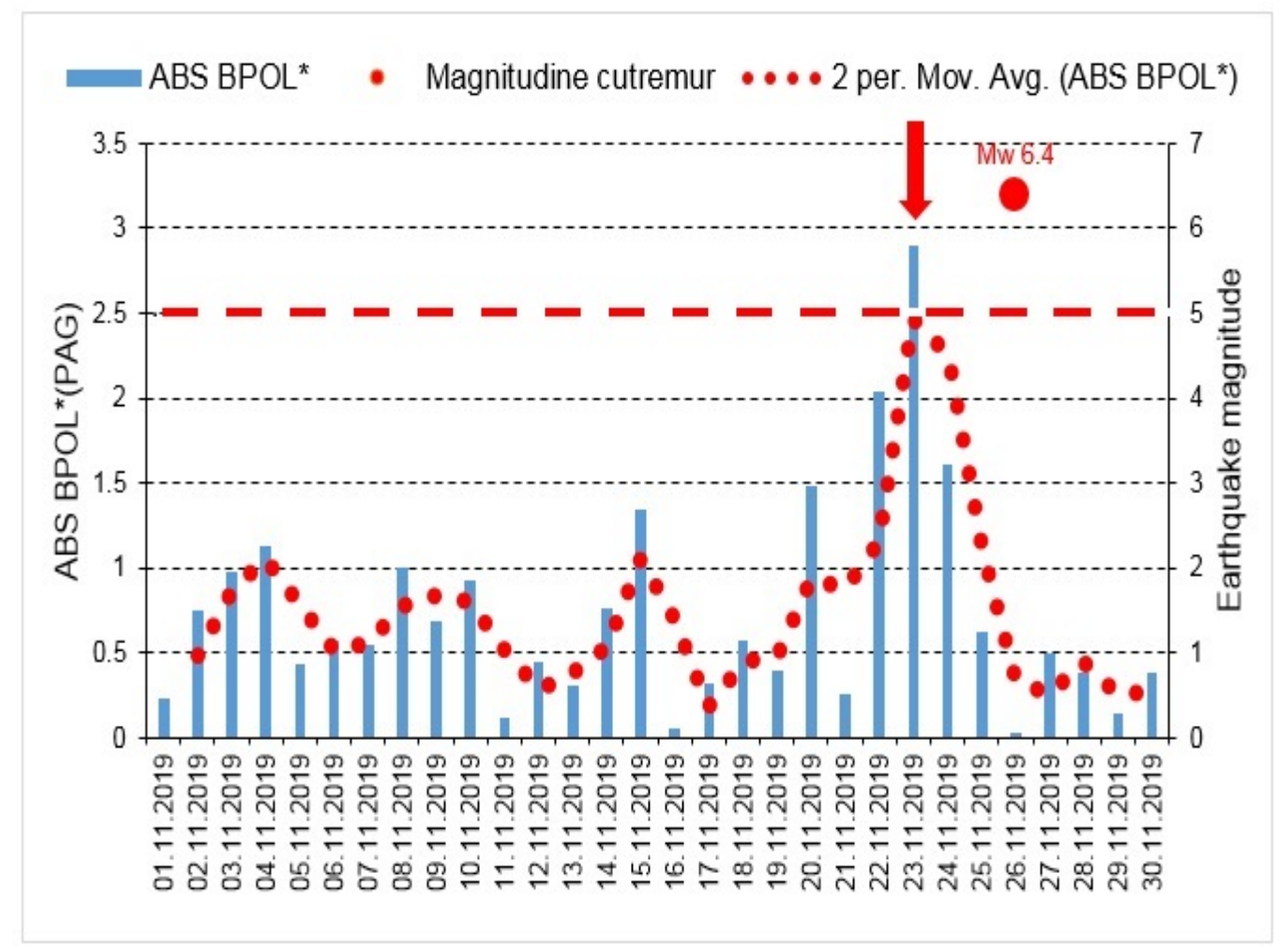

Figure 7. ABS BPOL* (PAG) time series carried out on the interval 1-30 November 2019; ABS is absolute value; for additional explanation see Figure 6 caption. 


\subsection{ABS BPOL* (PAG-SUA) Time Series Carried Out Using Relation (4)}

In the end, in Figure 8, on the time series distribution, it is emphasized an anomalous geomagnetic signal on 23 November, 2019 as a precursor of the Mw6.4, taking as reference PAG observatory.

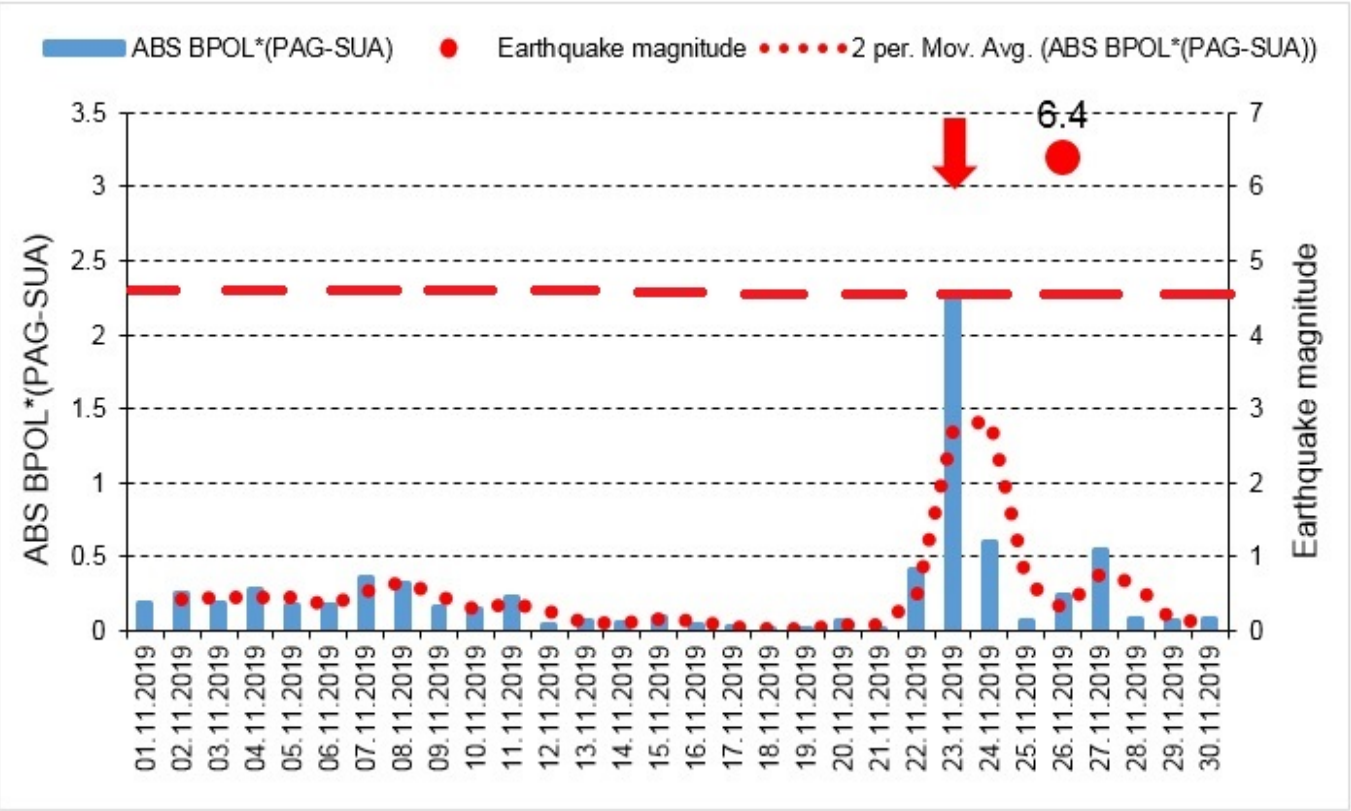

Figure 8. ABS BPOL* (PAG-SUA) time series; for more explanations see Figures 6 and 7 captions.

\section{Discussion and Conclusions}

With the aim to identify possible correlation between the pre-seismic geomagnetic signature and the coastal Mw6.4earthquake, in this paper we investigated the geomagnetic data recorded, on the interval 15 October-30 November, 2019, at the Panagjurishte (PAG), Bulgaria and Surlari (SUA), Romania, the first one taken as reference, and the following results are inferred as:

- The BPOL (PAG) and BPOL (SUA) time series obtained on the interval 1-30 November using (Relation 1), emphasize two pre-seismic anomalous signatures, extended on the intervals 21-27 November for PAG and 21-28 November for SUA, on which two maximum amplitudes were identified on 23 November (1.727 for PAG and 1.892 for SUA), with 3 days before the occurrence of Mw6.4earthquake. These results are presented in Section 3.1, Figures 4 and 5;

- A precursory signature associated to the above-mentioned earthquake was identified on the $\mathrm{BPOL}^{*}$ (PAG) and ABS BPOL* (PAG) time series carried out on the interval 1-30 November, using a statistical analysis based on Relation 3, and the results are emphasized in Section 3.2, Figures 6 and 7. On the both BPOL* (PAG) and ABS BPOL* (PAG) time series an anomalous interval, extended between 22 and 24 November, with a maximum value of 2.5 (Figures 6 and 7 ), was identified with 3 days before the Mw6.4 earthquake occurrence.

To differentiate the transient local anomalies related to the Mw6.4earthquake, by the internal and external parts of the geomagnetic field, we applied Relation 4 to obtain on the interval 1-30 November the ABS BPOL* (PAG-SUA) time series, the geomagnetic observatory (PAG) taken as reference. The result related to the pre-seismic geomagnetic signature, summarized in Section 3.3, Figure 8, consists of a very clear anomaly of maximum extended on 22-24 November, having an apex of about 2.274 on 23 November, identified on the BPOL* (PAG-SUA) time series, with 3 days prior to the onset of the M6.4 earthquake, so as it was indicated by threshold for anomaly (red dashed line). 
In conclusion, the above-mentioned results offer opportunities to develop geomagnetic methodologies for the earlier detection of specific pre-seismic anomalies related to the major earthquakes. Consequently, any a priori information related to a major seismic event occurrence, transmitted in time to the authorities responsible in this domain, represents an useful contribution for prevention, management, and decrease of the catastrophic risks.

Author Contributions: Conceptualization, D.A.S.; methodology, D.A.S.; software, D.A.S.; validation, D.A.S., and D.S.; writing—original draft preparation, D.A.S.; writing—review and editing, D.A.S. and D.S. All authors have read and agreed to the published version of the manuscript.

Funding: This research received no external funding.

Acknowledgments: In this paper, we used the data collected at the Geomagnetic Observatories located in Panagjurishte (PAG), Bulgaria and Surlari (SUA), Romania. We would like to thank the national institutes that support them and INTERMAGNET for promoting high standards of magnetic observatory practice (http:/ / www.intermagnet.org accessed on 7 February 2021). The authors are grateful to the anonymous reviewers for their comments and useful suggestions.

Conflicts of Interest: The authors declare no conflict of interest.

\section{References}

1. Hayakawa, M.; Hobara, Y.; Yasuda, Y.; Yamaguchi, H.; Ohta, K.; Izutsu, J.; Nakamura, T. Possible precursor to the March 11, 2011, Japan Earthquake: Ionospheric perturbations as seen by subionospheric very low frequency/low frequency propagation. Ann. Geophys. 2012, 55, 95-99. [CrossRef]

2. Nagao, T.; Orihara, Y.; Kamogawa, M. Precursory phenomena possibly related to the 2011 M9.0 off the Pacific coast of Tohoku earthquake. J. Disaster Res. 2014, 9, 303-310. [CrossRef]

3. Ouzounov, D.; Pulinets, S.; Romanov, A.; Romanov, A.; Tsybulya, K.; Davidenko, D. Kafatos, M.; Taylor, P. Atmosphere-ionosphere response to the $M 9$ Tohoku earthquake revealed by multi-instrument space-borne and ground observations: Preliminary results. Earthq. Sci. 2011, 24, 557-564. [CrossRef]

4. Sarlis, N.; Skordas, E.; Varotsos, P.; Nagao, T.; Kamogawa, M.; Tanaka, H.; Uyeda, S. Minimum of the order parameter fluctuations of seismicity before major earthquake in Japan. Proc. Natl. Acad. Sci. USA 2013, 110, 13734-13738. [CrossRef] [PubMed]

5. Hayakawa, M.; Schekotov, A.; Potirakis, S.; Eftaxias, K. Criticality features in ULF magnetic field prior to the 2011 Tohoku earthquake. Proc. Jpn. Acad. Ser. B 2015, 91, 25-30. [CrossRef] [PubMed]

6. Stanica, D.A.; Stanica, D.; Vladimirescu, N. Long-range anomalous electromagnetic effect related to M9 Great Tohoku earthquake. Earth Sci. 2015, 4, 31-38.

7. Stanica, D.A.; Stanica, D.; Blecki, J.; Ernst, T.; Jozwiak, W.; Slominski, J. Pre-seismic geomagnetic and ionosphere signatures related to the Mw5.7 earthquake occurred in Vrancea zone on September 24, 2016. Acta Geophys. 2018, 66, 167-177. [CrossRef]

8. Stanica, D.A.; Stanica, D. ULF pre-seismic geomagnetic anomalous signal related to Mw8.1 offshore Chiapas earthquake, Mexico on 8 September 2017. Entropy 2019, 21, 29. [CrossRef] [PubMed]

9. Stanica, D.A.; Stanica, D. Geomagnetic anomalous signal associated with Mw8.3 Coquimbo-Chile earthquake on September 16th, 2015. In Proceedings of the GEOSCIENCE 2019, Bucharest, Romania, 22 November 2019.

10. Stanica, D.A.; Stanica, D.; Valeca, M.; Iordache, S. Electromagnetic contribution to the resilience improvement against the Vrancea intermediate depth earthquakes, Romania. Ann. Geophys. 2020, 63, 551. [CrossRef]

11. Petraki, E.; Nikolopoulos, D.; Nomicos, C.; Stonham, J.; Cantzos, D.; Yannakopoulos, P.; Kottou, S. Electromagnetic pre-earthquake precursors: Mechanisms, data and models-A review. J. Earth Sci. Clim. Change 2015, 6, 250. [CrossRef]

12. Fitterman, D.V. Electrokinetic and magnetic anomalies associated with dilatant regions in a layered Earth. J. Geophys. Res. Solid Earth 1978, 83, 5923-5928. [CrossRef]

13. Sasai, Y. Tectonomagnetic modeling on the basis of the linear piezomagnetic effect. Bull. Earthq. Res. Inst. Univ. Tokyo. 1991, 66, 585-722.

14. Fitterman, D.V. Theory of electrokinetic-magnetic anomalies in a faulted half-space. J. Geophys. Res. Solid Earth 1979, 84, 6031-6040. [CrossRef]

15. Varotsos, P.; Alexopoulos, K.; Nomicos, K.; Lazaridou, M. Earthquake prediction on electric signals. Nature 1986, $322,120$. [CrossRef]

16. Ouzounov, D.; Pulinets, S.; Guiliani, G.; Velichkova-Istova, S.; Kafatos, M.; Taylor, P. Pre-Earthquake Processes Associated with the M6.4 of Nov 26, 2017 in Albania. A Multi Parameters Analysis. In Proceedings of the EGU General Assembly 2020, Online, 4-8 May 2020. [CrossRef]

17. Colonna, R.; Tramutoli, V.; Filizzola, C.; Genzano, N.; Lisi, M.; Pergola, N. Statistical Analysis for the Identification of Precursory Signatures of Earthquake Occurrence in Total Electron Content (TEC). In Proceedings of the EGU General Assembly 2020, Online, 4-8 May 2020. [CrossRef] 
18. Contadakis, M.E.; Arabelos, D.; Vergos, G.; Scordilis, E.M. Lower Ionospheric Turbulence Variations during the Intense Seismic Activity of the Last Half of 2019 in the Broader Balkan Region. In Proceedings of the EGU General Assembly 2020, Online, 4-8 May 2020. [CrossRef]

19. Biagi, P.F.; Nina, A.; Ermini, A.; Nico, G. Variations revealed by INFREP Radio Network in Correspondence of Six Earthquakes with MW Greater Than 5.0 Occurred in the Balkan Peninsula and Adriatic Sea on 26 and 27 November, 2019. In Proceedings of the EGU General Assembly 2020, Online, 4-8 May 2020. [CrossRef]

20. Moldovan, I.A.; Toader, V.E.; Oikonomou, C.; Haralambous, H.; Biagi, P.F.; Muntean, A.; Mihai, A.; Khadka, A. Investigation of Pre-Earthquake Ionospheric Anomalies Before Albania 2019 Earthquake Using the Romanian Receivers of the Vlf/Lf Infrep and Gnss Global European Networks. In Proceedings of the EGU General Assembly 2020, Online, 4-8 May 2020. [CrossRef]

21. Tramutoli, V.; Genzano, N.; Colonna, R.; Filizzola, C.; Lisi, M.; Pergola, N.; Satriano, V. Satellite Thermal Monitoring of Balkan Region by Means of Robust Satellite Techniques: The Case of Albania (26 November 2019, Mw 6.4) Earthquake. In Proceedings of the EGU General Assembly 2020, Online, 4-8 May 2020. [CrossRef]

22. Schmid, M.S.; Fügenschuh, B.; Kounov, A.; Matenco, L.; Nievergelt, P.; Oberhänsli, R.; Pleuger, J.; Schefer, S.; Schuster, R.; Tomljenović, B.; et al. Tectonic units of the Alpine collision zone between Eastern Alps and western Turkey. Gondwana Res. 2020, 78, 308-374. [CrossRef]

23. Hayakawa, M.; Kawate, R.; Molchanov, O.A.; Yumoto, K. Results of ultra-Low-frequency magnetic field measurements during the Guam earthquake of 8 August 1993. Geophys. Res. Lett. 1996, 23, 241-244. [CrossRef]

24. Morgunov, V.; Malzev, S. A multiple fracture model of pre-seismic electromagnetic phenomena. Tectonophysics 2007, 431, 61-72. [CrossRef] 